\title{
Papillary muscle infarction and cardiovascular outcomes
}

\author{
Geetha P Bhumireddy ${ }^{1 *}$, Nikolas Krishna ${ }^{1}$, Nripen Donneti ${ }^{1}$, On Chen ${ }^{1}$, ljaz Ahmad ${ }^{2}$, Quaratal Jamell ${ }^{2}$, \\ Joshua Socolow ${ }^{1}$, Sorin J Brener ${ }^{2}$, Igor Klem³ ${ }^{3}$, Joshua Fogel ${ }^{1}$, Terrence Sacchi ${ }^{1}$, John F Heitner ${ }^{1}$ \\ From 2011 SCMR/Euro CMR Joint Scientific Sessions \\ Nice, France. 3-6 February 2011
}

\section{Introduction}

Recent studies suggest that papillary muscle infarction (PMI) detected by contrast enhancement cardiac magnetic resonance (ce-CMR) may correlate with mitral regurgitation and reduced left ventricular ejection fraction (LVEF). However, there is scant data about the association of PMI with cardiovascular outcomes.

\section{Purpose}

To determine the prognostic significance of PMI, detected by ce-CMR, in patients with ischemic (ICM) and non-ischemic cardiomyopathy (NICM).

\section{Methods}

We evaluated the images of 456 consecutive patients who underwent ce-CMR for the assessment of left ventricular function and viability. PMI (both anterolateral and postero-medial papillary muscles), ICM and NICM were assessed by visual assessment by interpreters blinded to clinical data. All patients had a LVEF $\leq 50 \%$. ICM and NICM were determined by presence and pattern of hyper-enhancement. Patients were followed by telephone interview for the following outcomes: all-cause mortality, exacerbation of CHF, defined as a decrease in NYHA functional class, myocardial infarction or re-hospitalization due to a cardiac etiology.

\section{Results}

Our study population consisted of 320 patients with ICM and 136 with NICM (mean age: 63 years; males:
$66 \%$ ). The prevalence of PMI was $66 \%$ and $12 \%$ in the ICM and NICM patients, respectively. There was a higher prevalence of postero-medial PMI compared to antero-lateral PMI in both the ICM and NICM (66\% vs. $30 \%$ and $63 \%$ vs. $38 \%$ respectively). Mean follow up was $2.8 \pm 1.8$ years.

Presence of PMI was associated with a significantly higher incidence of all-cause mortality and cardiovascular outcomes ( $11 \%$ vs. $4 \%, p=0.02$ and $54 \%$ vs. $42 \%$ $\mathrm{p}=0.009$, respectively). Patients with both papillary muscles infarcted had a higher incidence of all-cause mortality and cardiovascular outcomes compared to patients with no PMI ( $30 \%$ vs. $4 \%, \mathrm{p}<0.01 ; 53 \%$ vs. $42 \%, \mathrm{p}<0.05)$. In addition, postero-medial PMI was associated with a higher incidence of cardiovascular outcomes and worsening of CHF compared to patients with no PMI ( $57 \%$ vs. $42 \%, \mathrm{p}<0.05 ; 38 \%$ vs. $27 \%$, $\mathrm{p}=0.019$ ). After multiple logistic regression analysis, both PMI and poster-medial PMI were independent predictors of cardiovascular outcomes, and patients who had both papillary muscles infarcted had a higher incidence of death (Table 1).

\section{Conclusions}

Papillary muscle infarction and postero-medial PMI are independent predictors of combined cardiovascular outcomes. Postero-medial PMI is more prevalent than antero-lateral PMI and is also an independent predictor of worsening CHF.

${ }^{1}$ New York Methodist Hospital, Brooklyn, NY, USA

Full list of author information is available at the end of the article

(C) 2011 Bhumireddy et al; licensee BioMed Central Ltd. This is an open access article distributed under the terms of the Creative 
Table 1 Univariate and multivariate logistic regression anlyses of cardiovascular (CV) outcomes

\begin{tabular}{|c|c|c|c|c|c|c|}
\hline Variable & Univariate analysis (Odds Ratio) & $95 \% \mathrm{Cl}$ & P-value & Multivarites analysis (Odds Ratio) & $95 \% \mathrm{Cl}$ & P-value \\
\hline \multicolumn{7}{|c|}{ Papillary muscle infarction } \\
\hline Death & 3.39 & $1.49-7.67$ & 0.003 & 2.05 & $0.82-5.0$ & 0.12 \\
\hline Combined CV outcome & 1.64 & 1.13-2.37 & 0.09 & 1.53 & $1.01-2.32$ & 0.04 \\
\hline \multicolumn{7}{|c|}{ Stratified by location and number of papillary muscle infarctions } \\
\hline \multicolumn{7}{|c|}{ Both postero-medial and antero-lateral } \\
\hline Death & 11.66 & 4.9-29.9 & $<0.001$ & 7.09 & $2.35-29.35$ & $<0.001$ \\
\hline Worsening CHF & 0.63 & $0.29-1.33$ & 0.25 & 0.50 & $0.21-1.17$ & 0.11 \\
\hline Combined CV outcome & 1.56 & $0.83-2.93$ & 0.16 & 1.32 & $0.66-2.63$ & 0.43 \\
\hline \multicolumn{7}{|l|}{ Postero-medial } \\
\hline Death & 1.6 & $0.96-2.64$ & 0.68 & 1.84 & $0.9-2.8$ & 0.7 \\
\hline Worsening CHF & 1.65 & $1.04-2.61$ & 0.03 & 1.60 & $0.96-2.64$ & 0.06 \\
\hline Combined CV outcome & 1.84 & $1.19-2.84$ & 0.006 & 1.73 & $1.07-2.77$ & 0.02 \\
\hline \multicolumn{7}{|l|}{ Antero-lateral } \\
\hline Death & 3.06 & $0.95-9.77$ & 0.06 & 2.16 & $0.61-7.62$ & 0.23 \\
\hline Worsening CHF & 0.67 & $0.31-1.42$ & 0.29 & 0.63 & $0.28-1.38$ & 0.25 \\
\hline Combined CV outcome & 1.30 & $0.68-2.34$ & 0.44 & 1.25 & $0.65-2.39$ & 0.49 \\
\hline \multicolumn{4}{|l|}{ Clinical variables } & \multicolumn{3}{|l|}{ Multivariate Analysis for Death } \\
\hline Age & & & & 1.031 & 0.99-1.06 & 0.008 \\
\hline Gender & & & & 1.47 & $0.63-3.41$ & 0.37 \\
\hline $\mathrm{CHF}$ & & & & 1.59 & $0.66-3.76$ & 0.29 \\
\hline Myocardial infarction & & & & 1.30 & $0.56-3.0$ & 0.54 \\
\hline Valve Dysfunction & & & & 2.54 & $1.1-5.39$ & 0.029 \\
\hline Ejection Fraction & & & & 0.97 & $0.94-1.0$ & 0.05 \\
\hline Smoking & & & & 0.43 & $0.05-3.38$ & 0.42 \\
\hline Hypertension & & & & 0.87 & $0.33-2.25$ & 0.77 \\
\hline Diabetes & & & & 1.43 & $0.65-3.12$ & 0.36 \\
\hline Revascularization & & & & 0.88 & $0.37-2.08$ & 0.77 \\
\hline
\end{tabular}

\section{Author details}

${ }^{1}$ New York Methodist Hospital, Brooklyn, NY, USA. ${ }^{2}$ New York Methodist

Hospital, New York, NY, USA. ${ }^{3}$ Duke Medical Center, Durham, NC, USA.

Published: 2 February 2011

doi:10.1186/1532-429X-13-S1-089

Cite this article as: Bhumireddy et al:: Papillary muscle infarction and cardiovascular outcomes. Journal of Cardiovascular Magnetic Resonance 2011 13(Suppl 1):O89.

Submit your next manuscript to BioMed Central and take full advantage of:

- Convenient online submission

- Thorough peer review

- No space constraints or color figure charges

- Immediate publication on acceptance

- Inclusion in PubMed, CAS, Scopus and Google Scholar

- Research which is freely available for redistribution

Submit your manuscript at www.biomedcentral.com/submit
C Biomed Central 